\title{
CRESCIMENTO, PRODUTIVIDADE E PALHADA DE MILHO EXCLUSIVO E CONSORCIADO COM CROTALÁRIAS EM DIFERENTES ESPAÇAMENTOS
}

\author{
VINÍCIUS CAMBAÚVA ${ }^{1}$, FÁBIO TIRABOSCHI LEAL ${ }^{1}$ e LEANDRO BORGES LEMOS ${ }^{1}$
}

\author{
${ }^{1}$ Universidade Estadual Paulista, Faculdade de Ciências Agrárias e Veterinárias (UNESP/FCAV), \\ Via de Acesso Prof. Paulo Donato Castellane, s/n, 14884-900 - Jaboticabal, SP, Brasil. \\ viniciuscambauva@hotmail.com,lealft@bol.com.br,leandrobl@fcav.unesp.br
}

Revista Brasileira de Milho e Sorgo, v.18, n.1, p. 99-111, 2019

\begin{abstract}
RESUMO - A escolha da espécie de crotalária associada ao adequado espaçamento entrelinhas de milho possibilita o retorno econômico com o cereal e os benefícios dos adubos verdes. Assim, o objetivo desse trabalho foi avaliar o crescimento e desempenho agronômico do milho, a quantidade e o acúmulo de nitrogênio na palhada provenientes dos sistemas de cultivo de milho exclusivo e consorciado com Crotalaria juncea, Crotalaria spectabilis e Crotalaria ochroleuca e a mistura dessas espécies ("mix"). O delineamento experimental foi o de blocos casualizados, em esquemas de parcelas subdivididas, com quatro repetições. As parcelas foram compostas por dois espaçamentos entrelinhas de milho: 0,45 e $0,90 \mathrm{~m}$. As subparcelas foram compostas por cinco sistemas de cultivo: milho exclusivo; milho + C. juncea; milho + C. spectabilis; milho + C. ochroleuca; milho + "mix" (C. juncea, C. spectabilis e C. ochroleuca). O consórcio com a $C$. juncea reduz a produtividade do cereal. No entanto, sua utilização no "mix" é viável. Os espaçamentos de 0,45 e 0,90 m não influenciam o crescimento e a produtividade do milho, e a palhada dos sistemas de cultivo. Os consórcios com crotalárias proporcionam maior quantidade de palhada em comparação ao milho exclusivo, embora o acúmulo de nitrogênio não seja alterado.
\end{abstract}

Palavras-chave: Zea mays L., Crotalaria juncea, Crotalaria spectabilis, Crotalaria ochroleuca, adubos verdes.

\section{GROWTH, YIELD AND STRAW OF EXCLUSIVE AND INTERCROPPED MAIZE WITH CROTALARIAS IN DIFFERENT ROW SPACINGS}

\begin{abstract}
The choice of the crotalaria species associated to the adequate maize row spacing allows the economic return with the cereal and the benefits of the green fertilizers. Thus, the objective of this work was to evaluate the growth and agronomic performance of maize, the amount and nitrogen accumulation in the straw from the exclusive and intercropped systems of maize with Crotalaria juncea, Crotalaria spectabilis and Crotalaria ochroleuca, and the mixture of these species ("mix"). A randomized complete block design with four replications was used. The plots were composed of two maize row spacings, 0.45 and $0.90 \mathrm{~m}$. The subplots were constituted of five systems: exclusive maize; maize + C. juncea; maize + C. spectabilis; maize + C. ochroleuca; maize + "mix" (C. juncea, C. spectabilis and C. ochroleuca). The consortium with $C$. juncea reduced cereal productivity. However, its use in the "mix" is feasible. Rows spacings of 0.90 and $0.45 \mathrm{~m}$ did not affect maize growth and yield, and straw of systems. The consortium with crotalaria provided more straw compared to exclusive maize, although the $\mathrm{N}$ accumulation did not change.
\end{abstract}

Keywords: Zea mays L., Crotalaria juncea, Crotalaria spectabilis, Crotalaria ochroleuca, green manure crops. 
$\mathrm{Na}$ agricultura brasileira, dentre as espécies consideradas adubos verdes, destacam-se as do gênero Crotalaria, podendo-se citar a $C$. juncea, $C$. spectabilis, C. ochroleuca e C. breviflora. Essas plantas se destacam principalmente pela habilidade de fixar nitrogênio (N) ao solo, ciclar nutrientes, reestruturar quimicamente e fisicamente os solos, aumentar a taxa de infiltração de água no solo, controlar nematoides e suprimir plantas daninhas. O cultivo dessas espécies é, em geral, recomendado para sistemas de sucessão/rotação de culturas, tendo também potencial para uso em sistemas de consórcio, por serem plantas anuais, eretas, arbustivas e de crescimento determinado (Oliveira et al., 2010; Wutke et al., 2014).

Nesse sentido, o milho é recomendado para o consórcio de culturas, por apresentar vantagem competitiva, com eficiência fotossintética e interceptação de radiação luminosa (metabolismo de fixação de carbono $\mathrm{C}_{4}$ ), porte alto e rápido crescimento inicial. O sistema de cultivo consorciado possibilita o melhor aproveitamento do ano agrícola, tendo, no mesmo período, o retorno econômico com a produção de grãos do cereal e os benefícios do adubo verde (Oliveira et al., 2010; Wutke et al., 2014; Kappes \& Zancanaro, 2015). A técnica de cultivo de milho em consórcio com adubos verdes, em especial com a $C$. spectabilis e o guandu -anão (Cajanus cajan), vem sendo desenvolvida pela Embrapa e denominada Sistema Santa Brígida (Oliveira et al., 2010).

As espécies de crotalárias se distinguem em relação aos aspectos morfofisiológicos (Wutke et al., 2014), como altura de planta, produção de massa verde e seca, extração e liberação de nutrientes e crescimento radicular, podendo alterar o desempenho produtivo da cultura do milho por causa da maior ou menor competição por luz e nutrientes (Gitti et al., 2012; Kappes \& Zancanaro, 2015). A C. juncea é aquela que pode ter maior competição com a cultura do milho em razão do maior crescimento de suas raízes e parte aérea (Wutke et al., 2014). Assim, a mistura de crotalárias ("mix") pode ser uma alternativa para se obter o benefício dessa espécie, sem prejuízos ao cereal, visto que a densidade de semeadura é reduzida.

Além disso, deve-se levar em consideração que mudanças no espaçamento entrelinhas das plantas de milho em consórcio podem promover alterações na competição intra e interespecífica, principalmente pela interferência na interceptação luminosa, afetando o crescimento e desenvolvimento das plantas (Gitti et al., 2012; Takasu et al., 2014; Kappes \& Zancanaro, 2015). Os espaçamentos de 0,45 e 0,90 m são utilizados com grande frequência no cultivo de milho. No entanto, há carência de estudos que avaliam o consórcio de crotalárias em diferentes espaçamentos entrelinhas do cereal.

Outro ponto que deve ser considerado em estudos sobre consórcios é a formação e composição da palhada oriunda desses sistemas de cultivo, principalmente visando a sustentabilidade do sistema de plantio direto e a sucessão de culturas (Silva et al., 2009). Essas palhadas podem apresentar distintas quantidades de massa seca e acúmulos de $\mathrm{N}$ em razão de diferentes capacidades de fixação desse nutriente e acúmulo de biomassa pelas espécies de crotalárias.

Assim, o objetivo com esse trabalho foi avaliar o crescimento e o desempenho agronômico da cultura do milho, e a quantidade e o acúmulo de $\mathrm{N}$ na palhada provenientes dos sistemas de cultivo de milho exclusivo e consorciado com $C$. juncea, $C$. spectabilis e $C$. ochroleuca e o "mix" dessas espécies. 


\section{Material e Métodos}

O experimento foi conduzido durante a safra verão, no ano agrícola 2016/17 na área experimental da Faculdade de Ciências Agrárias e Veterinárias, UNESP Campus de Jaboticabal - São Paulo, situada na latitude $21^{\circ} 15^{\prime} 22^{\prime \prime} \mathrm{S}$ e longitude de $48^{\circ} 18^{\prime} 58^{\prime \prime} \mathrm{W}$, em altitude média de 586 metros, e em solo classificado como Latossolo Vermelho eutroférrico, textura argilosa. O clima é do tipo Cwa de acordo com a classificação proposta por Köppen, sendo caracterizado como subtropical com inverno curto e seco e com verões quentes e chuvosos.

A área experimental se encontrava sob o sistema de preparo de solo convencional, sendo aplicado calcário (PRNT $=90 \%)$ na dose de $1 \mathrm{t} \mathrm{ha}^{-1}$, seguido por operações de incorporação (aração e gradagem). Antes da instalação do experimento, a área permaneceu em pousio no inverno-primavera, tendo como culturas anteriores milho no verão do ano agrícola 2015/16 e tremoço no verão de 2014/15.

Antes da implantação do experimento foram realizadas coletas de amostras de solo para determinação dos atributos químicos das camadas de 0-10 $\mathrm{cm}$ e $10-20 \mathrm{~cm}$. Os resultados paras as camadas $0-10$ $\mathrm{cm}$ e $10-20 \mathrm{~cm}$, respectivamente, foram $\mathrm{pH}\left(\mathrm{CaCl}_{2}\right)$ 5,7 e 5,$8 ; \mathrm{MO}=29$ e $26 \mathrm{~g} \mathrm{dm}^{-3} ; \mathrm{P}($ resina $)=13$ e $11 \mathrm{mg} \mathrm{dm}^{-3} ; \mathrm{K}=5,0$ e $5,3 \mathrm{mmol}_{\mathrm{c}} \mathrm{dm}^{-3} ; \mathrm{Ca}=34$ e 37 $\mathrm{mmol}_{\mathrm{c}} \mathrm{dm}^{-3} ; \mathrm{Mg}=17$ e $19 \mathrm{mmol}_{\mathrm{c}} \mathrm{dm}^{-3} ; \mathrm{S}=8$ e $10 \mathrm{mg}$ $\mathrm{dm}^{-3} ; \mathrm{H}+\mathrm{Al}=24$ e $18 \mathrm{mmol}_{\mathrm{c}} \mathrm{dm}^{-3} ; \mathrm{CTC}=80,0$ e 78,7 $\mathrm{mmol}_{\mathrm{c}} \mathrm{dm}^{-3}$ e $\mathrm{V}=70$ e $77 \%$.

O delineamento experimental foi o de blocos casualizados, em esquemas de parcelas subdivididas, com quatro repetições. As parcelas foram compostas por dois espaçamentos entrelinhas de milho: 0,45 m e $0,90 \mathrm{~m}$. As subparcelas foram compostas por cinco sistemas de cultivo, exclusivo e consorciado: milho
+ Crotalaria juncea; milho + Crotalaria spectabilis; milho + Crotalaria ochroleuca; milho + Mistura das espécies (C. juncea, C. spectabilis e C. ochroleuca); e milho exclusivo. Cada subparcela foi formada por 6 linhas de milho com cinco metros de comprimento, sendo consideradas úteis as quatro linhas centrais.

A semeadura das espécies das crotalárias foi feita a lanço manualmente e incorporada durante a semeadura mecanizada do milho (simultaneamente). A densidade para os sistemas com $C$. juncea, $C$. spectabilis e C. ochroleuca foi de $15 \mathrm{~kg} \mathrm{ha}^{-1}$, e para a mistura de espécies ("mix") foi adotado $5 \mathrm{~kg} \mathrm{ha}^{-1} \mathrm{de}$ cada espécie, totalizando os mesmos $15 \mathrm{~kg} \mathrm{ha}^{-1}$. Foi utilizado o híbrido de milho Dow 2B710, na densidade de 66.000 plantas ha-1 . Esse híbrido é caracterizado por ter porte baixo, ciclo precoce, alto potencial produtivo e sementes comercializadas com tratamento de sementes industrial. Não foi realizado nenhum manejo específico nas espécies de crotalária durante a condução do experimento.

A semeadura do milho e das espécies de crotalária ocorreu em 22 de novembro de 2016. Os cálculos para adubação de semeadura foram realizados de acordo com a análise de solo e histórico da área, e conforme recomendações sugeridas por Raij e Cantarella (1997). Para a adubação de semeadura, a dose utilizada foi $250 \mathrm{~kg} \mathrm{ha}^{-1}$ do formulado 8-28-16 aplicada no sulco de semeadura. A adubação de cobertura foi realizada por ocasião dos estádios fenológicos $V_{4}$ (quarta folha mais alta, cuja aurícula seja visível) e $\mathrm{V}_{6}$ (sexta folha mais alta, cuja aurícula seja visível), via formulado 20-00-20 $\left(\mathrm{V}_{4}\right)$, com dose de $400 \mathrm{~kg} \mathrm{ha}^{-1}$, e ureia convencional $\left(\mathrm{V}_{6}\right)$, com dose de $136 \mathrm{~kg} \mathrm{ha}^{-1}$, respectivamente, distribuídos em filetes contínuos a $10 \mathrm{~cm}$ acima da linha do milho. Após as aplicações dos fertilizantes em cobertura ocorreram chuvas de 9,2 e 10,5 mm, respectivamente (Figura 1). 


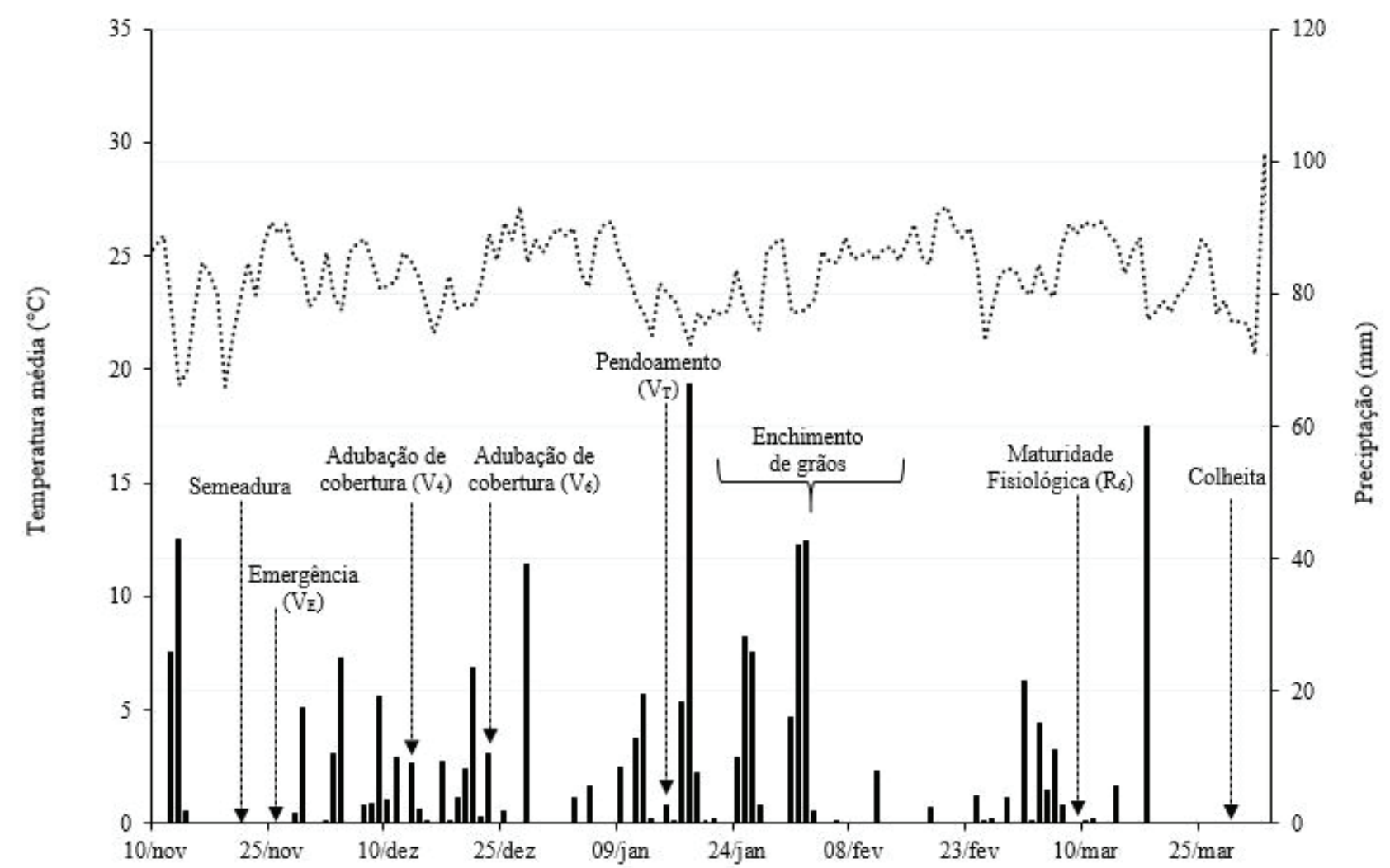

Figura 1. Precipitação pluvial e temperatura média diárias durante a condução do experimento. Semeadura em 22 de novembro, emergência $\left(V_{E}\right)$ em 27 de novembro, pendoamento $\left(V_{T}\right)$ em 16 de janeiro, enchimento de grãos entre 24 de janeiro e 15 de fevereiro, maturidade fisiológica $\left(R_{6}\right)$ em 09 de março e colheita em 31 de março. Fonte: Estação Agroclimatológica do Campus da FCAV/UNESP - Jaboticabal, SP.

Durante a condução do experimento, foi adotado o manejo de irrigação utilizando o sistema do tipo aspersão convencional, com turno de rega de 3 a 4 dias e lâmina de $10 \mathrm{~mm}$ por turno, tendo sido realizada até o estádio $\mathrm{V}_{4}$.

Com relação aos tratamentos fitossanitários, e levando em consideração a avaliação de pragas e doenças e seus respectivos níveis de controle, não foi necessária a pulverização de inseticidas e fungicidas na cultura. Foi realizada a capina manual para evitar interferências de plantas daninhas nos sistemas de cultivos de milho, apenas uma única vez, no estádio vegetativo $\mathrm{V}_{6}$ do milho.
$\mathrm{Na}$ cultura do milho, foram realizadas as seguintes avaliações:

a) Teor de $\mathrm{N}$ total foliar $\left(\mathrm{g} \mathrm{kg}^{-1}\right)$ - no florescimento feminino $\left(R_{1}\right)$ foram coletadas em dez plantas por subparcela, o terço central de dez folhas localizadas abaixo e opostas à espiga principal, excluindo-se a nervura central (Coelho et al., 2002). O material vegetal foi lavado com água corrente e solução aquosa de detergente a $1 \%$, e posteriormente, seco em estufa com circulação forçada de ar sob temperatura de 65 a $70{ }^{\circ} \mathrm{C}$ até massa constante. Depois de secas as amostras, essas foram moídas em moinho do tipo Wiley e em 
seguida levadas à digestão sulfúrica para determinação do teor de $\mathrm{N}$.

b) Altura final de plantas ( $m$ ) - foi determinado no estádio de maturidade fisiológica $\left(\mathrm{R}_{6}\right)$ do milho, medindo-se dez plantas ao acaso, com auxílio de uma régua, a distância do nível do solo até a inserção da última folha.

c) Altura de inserção da espiga principal (m) - foi medida a distância entre o colo da planta e a inserção da espiga principal, em amostras de 10 plantas, tomadas ao acaso, dentro da área útil de cada subparcela.

d) Diâmetro do colmo ( $\mathrm{mm})$ - foi medido utilizando um paquímetro (expresso em milímetros), na altura de $10 \mathrm{~cm}$ em relação ao solo, em 5 plantas, tomadas ao acaso, dentro da área útil de cada subparcela.

e) Número de fileiras e grãos por espiga - no momento da colheita, foram retiradas cinco espigas representativas de cada parcela para contagem do número de fileiras e de grãos em cada fileira, chegandose ao número de grãos por espiga.

f) Massa de 1.000 grãos (g) - foi determinada pela coleta ao acaso e pesagem de quatro amostras de 300 grãos, representando a área útil de cada subparcela, que foram convertidas à massa de 1.000 grãos, com correção dos valores para $0,13 \mathrm{~kg} \mathrm{~kg}^{-1} \mathrm{em}$ base úmida.

g) Produtividade de grãos $\left(\mathrm{kg} \mathrm{ha}^{-1}\right)$ - após a maturidade dos grãos, foi efetuada a colheita manual das espigas da área útil em cada subparcela, sendo posteriormente trilhadas mecanicamente, determinando-se a produtividade de grãos, corrigindo-se o teor de água para $0,13 \mathrm{~kg} \mathrm{~kg}^{-1}$ em base úmida.

h) Prolificidade - durante a colheita, foi realizada a contagem do número de plantas e espigas com grãos na área útil da subparcela. A prolificidade foi calculada pela relação entre o número de espigas e o número de plantas para obtenção dos dados.

i) Diâmetro da espiga (DE) - foi medido com a utilização de um paquímetro (expresso em milímetros), em cinco espigas, selecionadas ao acaso na área útil de cada subparcela.

j) Diâmetro do sabugo (DS) - foi medido com a utilização de um paquímetro (expresso em milímetros), após a debulha das cinco espigas selecionadas para a avaliação do diâmetro da espiga.

k) DE - DS - foi obtida pela diferença entre diâmetro da espiga diâmetro do sabugo a fim de estabelecer uma média que representasse o tamanho dos grãos de milho.

1) Peso do Sabugo - obtido pela pesagem dos cinco sabugos utilizados nas avaliações anteriores; sabugos selecionados aleatoriamente na avaliação anterior.

Nas plantas de crotalárias foi realizada a seguinte avaliação:

a) Altura final das plantas (m) - foi determinada no estádio de maturidade fisiológica $\left(\mathrm{R}_{6}\right)$ do milho, medindo-se dez plantas ao acaso, com auxílio de uma régua, a distância do nível do solo até a inserção da última folha.

$\mathrm{Na}$ cobertura vegetal sob solo foram feitas as seguintes avaliações:

a) Produção de palhada ou matéria seca $\left(\mathrm{t} \mathrm{ha}^{-1}\right)$ - foi utilizado um quadro de madeira com dimensões internas de 0,5 m x 0,5 m, sendo coletadas duas amostras correspondentes a cada subparcela, que foram submetidas à lavagem e secas em estufa de ventilação forçada de ar a 65 a $70{ }^{\circ} \mathrm{C}$ até massa constante.

b) Teor e acúmulo de $\mathrm{N}$ na palhada $\left(\mathrm{g} \mathrm{kg}^{-1}\right)$ após a determinação da produção de palhada produzi- 
da, o material foi submetido à lavagem em água deionizada, conduzido à estufa de circulação de ar forçada sob temperatura de 65 a $70{ }^{\circ} \mathrm{C}$ até massa constante, moído e levado para digestão sulfúrica e, em seguida, foi realizada a determinação do teor de N. Com os resultados da quantidade de palhada (matéria seca) produzida e os respectivos teores de $\mathrm{N}$, foi calculado o acúmulo do nutriente nos diferentes sistemas de cultivo.

Os dados obtidos foram analisados pelo teste F, e as médias, comparadas pelo teste de Tukey a 5\% de probabilidade.

\section{Resultados e Discussão}

Os teores de $\mathrm{N}$ na folha do milho não apresentaram diferenças significativas em função do sistema de cultivo e do espaçamento entrelinhas do milho (Tabela 1). Os valores médios dos teores desse nutriente na folha diagnóstica variaram entre 27,9 e $30,5 \mathrm{~g} \mathrm{~kg}^{-1}$ de $\mathrm{N}$, que se enquadram dentro da faixa de teores considerada adequada (27 a $35 \mathrm{~g} \mathrm{~kg}^{-1}$ ) para o milho (Cantarella et al., 1997). Esses resultados sugerem que a inserção das espécies de crotalária não alterou a nutrição do cereal em relação ao N. Não houve diferença significativa nos teores de $\mathrm{N}$ foliar em relação aos espaçamentos, indicando que diferentes arranjos espaciais das plantas de milho são viáveis para os sistemas de cultivo em consórcio com crotalárias. Heinrichs et al. (2002) verificaram que a nutrição da cultura do milho em $\mathrm{N}$ não foi influenciada pelo consórcio com adubos verdes, quando semeados simultaneamente com o cereal, no primeiro ano de cultivo. Além disso, Kaneko et al. (2010) constataram que os teores de $\mathrm{N}$ na folha permaneceram na faixa adequada, mesmo quando há redução no espaçamento entrelinhas do cereal.
O diâmetro do colmo e a altura final da planta de milho foram influenciados pelos sistemas de cultivo (Tabela 2). Os valores para essas variáveis foram reduzidos em relação ao milho exclusivo com a inserção da $C$. juncea no consórcio. Chieza et al. (2017) verificaram que o cultivo simultâneo de $C$. juncea com milho reduziu a produção de massa seca da parte aérea do cereal em $23 \%$ comparado ao seu monocultivo, o que também pode ter ocorrido nesse experimento visto que plantas de milho menores e com colmos mais finos podem resultar em menores acúmulos de massa seca. Kappes e Zancanaro (2015) observaram menores diâmetros de colmo do milho consorciado com C. juncea, independentemente do método de implantação (linha, entrelinhas, a lanço). Esses resultados sugerem que a competição por luminosidade entre o milho e a $C$. juncea pode ter ocasionado redução desse parâmetro para o cereal (Pereira et al., 2011). No entanto, não foram verificadas reduções nesses parâmetros quando utilizadas as demais crotalárias e a mistura dessas espécies, indicando que $C$. spectabilis, C. ochroleuca e C. juncea, em densidade de semeadura menor no "mix", não competem com o milho por luz na modalidade de consórcio utilizada nesse experimento. Os espaçamentos não influenciaram significativamente o diâmetro do colmo e a altura final do milho.

A altura de inserção da espiga principal não foi alterada pelos sistemas de cultivo e pelos espaçamentos (Tabela 2). Kappes et al. (2011) também não constataram diferença nesse parâmetro quando houve redução do espaçamento entrelinhas de $0,90 \mathrm{~m}$ para 0,45 m. A avaliação dessa característica é de grande importância agronômica sob a ótica de colheita do cereal, uma vez que as vagens contendo sementes das leguminosas não podem ser colhidas para evitar contaminação e/ou inutilização do lote. 
Tabela 1. Teores de nitrogênio na folha do milho em função dos sistemas de cultivo e do espaçamento entrelinhas de milho.

\begin{tabular}{cc}
\hline Tratamentos & Teor de N na folha $\left(\mathrm{g} \mathrm{kg}^{-1}\right)$ \\
\hline Sistemas de cultivo (SC) & $29,4 \mathrm{a}$ \\
Milho + C. juncea & $29,7 \mathrm{a}$ \\
Milho + C. spectabilis & $28,2 \mathrm{a}$ \\
Milho + C. ochroleuca & $27,9 \mathrm{a}$ \\
Milho + "mix" (crotalárias) & $30,5 \mathrm{a}$ \\
Milho exclusivo & 3,87 \\
\hline DMS Tukey & 9,00 \\
CV (\%) & $29,5 \mathrm{a}$ \\
\hline Espaçamentos (E) & $28,7 \mathrm{a}$ \\
0,90 m & 2,83 \\
0,45 m & 9,67 \\
\hline DS Tukey $(\%)$ & $1,35^{\mathrm{ns}}$ \\
Teste F & $0,81^{\mathrm{ns}}$ \\
SC & $0,69^{\mathrm{ns}}$ \\
\hline EC &
\end{tabular}

Médias seguidas pela mesma letra minúscula na coluna não diferem entre si pelo teste Tukey a 5\% de probabilidade; *,** significativo a 5 e $1 \%$ de probabilidade, respectivamente e ns - não significativo pelo teste $\mathrm{F}$.

Com relação à altura final da crotalária, a $C$. juncea apresentou as maiores alturas em consórcio com o milho (Tabela 2). Em condições normais de crescimento, as espécies de $C$. juncea e $C$. spectabilis podem atingir de 3,0 a 3,5 $\mathrm{m}$ e de 1,0 a 1,5 $\mathrm{m}$ de altura, respectivamente (Wutke et al., 2014). Pode-se observar, no presente trabalho, que a altura da $C$. juncea é muito superior às demais crotalárias, o que corrobora com o fato de que a $C$.juncea competiu por luz com o milho, diminuindo o diâmetro do colmo e a altura do milho. Além disso, é importante destacar que a $C$. juncea foi a única espécie que apresentou altura média superior à do cereal, em 0,46 m. A altura final das crotalárias foi alterada significativamente em função dos espaçamentos, sendo obtido menor valor na adoção do espaçamento entrelinhas de 0,45 m. Borghi e Crusciol (2007) constataram decréscimo na produção de matéria seca de braquiária no consórcio com milho em função da diminuição do espaçamento entrelinhas para 0,45 m. Os mesmos autores explicaram a redução da biomassa das plantas de cobertura por causa do maior sombreamento na fase inicial de desenvolvimento do milho, uma vez que a diminuição do espaçamento entrelinhas promove alteração no arranjo espacial, afetando a utilização desse recurso.

Os sistemas de cultivo influenciaram significativamente o diâmetro da espiga do milho (Tabela 3). O sistema de cultivo Milho + C. juncea resultou nos 
Tabela 2. Diâmetro do colmo, altura da planta de milho, altura de inserção da espiga principal e altura das crotalárias.

\begin{tabular}{|c|c|c|c|c|}
\hline Tratamentos & $\begin{array}{l}\text { Diâmetro do } \\
\text { colmo (mm) }\end{array}$ & $\begin{array}{l}\text { Altura final da } \\
\text { planta de milho } \\
\text { (m) }\end{array}$ & $\begin{array}{c}\text { Altura de } \\
\text { inserção da } \\
\text { espiga (m) }\end{array}$ & $\begin{array}{l}\text { Altura final da } \\
\text { crotalária }(\mathrm{m})\end{array}$ \\
\hline \multicolumn{5}{|l|}{ Sistemas de cultivo (SC) } \\
\hline Milho $+C$. juncea & $19,37 \mathrm{~b}$ & $2,50 \mathrm{~b}$ & $1,21 \mathrm{a}$ & $2,96 \mathrm{a}$ \\
\hline Milho + C. spectabilis & $20,81 \mathrm{ab}$ & $2,57 \mathrm{ab}$ & $1,23 \mathrm{a}$ & $1,24 \mathrm{~b}$ \\
\hline Milho $+C$. ochroleuca & $20,58 \mathrm{ab}$ & $2,55 \mathrm{ab}$ & $1,23 \mathrm{a}$ & $1,30 \mathrm{~b}$ \\
\hline Milho + "mix" (crotalárias) & $21,20 \mathrm{a}$ & $2,55 \mathrm{ab}$ & $1,22 \mathrm{a}$ & $1,45 \mathrm{~b}$ \\
\hline Milho exclusivo & $21,66 \mathrm{a}$ & $2,58 \mathrm{a}$ & $1,23 \mathrm{a}$ & - \\
\hline DMS Tukey & 1,67 & 0,07 & 0,06 & 0,21 \\
\hline $\mathrm{CV}(\%)$ & 5,47 & 2,02 & 3,41 & 8,58 \\
\hline \multicolumn{5}{|l|}{ Espaçamentos (E) } \\
\hline $0,90 \mathrm{~m}$ & $20,19 \mathrm{a}$ & $2,52 \mathrm{a}$ & $1,21 \mathrm{a}$ & $1,80 \mathrm{a}$ \\
\hline $0,45 \mathrm{~m}$ & $21,26 \mathrm{a}$ & $2,58 \mathrm{a}$ & $1,23 \mathrm{a}$ & $1,67 \mathrm{~b}$ \\
\hline DMS Tukey & 1,29 & 0,16 & 0,07 & 0,12 \\
\hline $\mathrm{CV}(\%)$ & 6,22 & 6,33 & 5,99 & 6,32 \\
\hline \multicolumn{5}{|l|}{ Teste F } \\
\hline $\mathrm{SC}$ & $4,59 * *$ & $2,87 *$ & $0,19^{\text {ns }}$ & $241,18 * *$ \\
\hline $\mathrm{E}$ & $6,83^{\mathrm{ns}}$ & $1,14^{\text {ns }}$ & $0,92^{\mathrm{ns}}$ & $11,91 *$ \\
\hline $\mathrm{SC} \times \mathrm{E}$ & $1,12^{\mathrm{ns}}$ & $0,32^{\text {ns }}$ & $0,16^{\mathrm{ns}}$ & $2,63^{\mathrm{ns}}$ \\
\hline
\end{tabular}

Médias seguidas pela mesma letra minúscula na coluna não diferem entre si pelo teste Tukey a $5 \%$ de probabilidade; *, ** significativo a 5 e $1 \%$ de probabilidade, respectivamente e ns - não significativo pelo teste $\mathrm{F}$.

menores diâmetros comparado ao Milho exclusivo, Milho + "mix" (crotalárias) e Milho + C. spectabilis, que não diferem do Milho + C. ochroleuca. Nesse sentido, o diâmetro do sabugo foi reduzido para os sistemas de cultivo de Milho + C. spectabilis e Milho + C. ochroleuca, em relação ao sistema de Milho exclusivo, que não diferiu dos sistemas de Milho com "mix" (crotalárias) e C. spectabilis. Por outro lado, a relação DE-DS, que estima o comprimento dos grãos de milho, não apresentou diferença para os sistemas de cultivos e espaçamentos, indicando que o tamanho dos grãos do milho não foi influenciado pelos tratamentos utilizados.
O peso do sabugo também foi reduzido no consórcio Milho $+C$. juncea em relação ao Milho exclusivo, que não teve diferenças significativas em relação aos demais. Esses resultados contrariam o que foi observado por Gitti et al. (2012), que não encontraram interferência da espécie em consórcio com a cultura do milho para essa variável. Para os espaçamentos, houve a redução dessa característica quando utilizado o espaçamento de $0,45 \mathrm{~m}$ entrelinhas de milho, o que sugere uma interferência do arranjo espacial na formação das estruturas reprodutivas do vegetal (Silva et al., 2014). Esse tipo de avaliação é importante para entender se as condi- 
Tabela 3. Diâmetro da espiga (DE), diâmetro do sabugo (DS), relação DE-DS e peso do sabugo.

\begin{tabular}{|c|c|c|c|c|}
\hline Tratamentos & $\begin{array}{l}\text { Diâmetro da } \\
\text { espiga (mm) }\end{array}$ & $\begin{array}{l}\text { Diâmetro do } \\
\text { sabugo (mm) }\end{array}$ & DE-DS (mm) & $\begin{array}{c}\text { Peso do } \\
\text { sabugo }(\mathrm{g})\end{array}$ \\
\hline \multicolumn{5}{|l|}{ Sistemas de cultivo (SC) } \\
\hline Milho $+C$. juncea & $51,25 \mathrm{~b}$ & $30,60 \mathrm{~b}$ & $20,64 \mathrm{a}$ & $27,20 \mathrm{~b}$ \\
\hline Milho + C. spectabilis & $52,60 \mathrm{a}$ & $31,47 \mathrm{ab}$ & $21,13 \mathrm{a}$ & $32,06 \mathrm{ab}$ \\
\hline Milho + C. ochroleuca & $52,01 \mathrm{ab}$ & $30,74 \mathrm{~b}$ & $21,26 \mathrm{a}$ & $31,61 \mathrm{ab}$ \\
\hline Milho + "mix" (crotalárias) & $52,98 \mathrm{a}$ & $32,04 \mathrm{ab}$ & $20,94 \mathrm{a}$ & $31,05 \mathrm{ab}$ \\
\hline Milho exclusivo & $52,67 \mathrm{a}$ & $32,32 \mathrm{a}$ & $20,35 \mathrm{a}$ & $33,21 \mathrm{a}$ \\
\hline DMS Tukey & 1,22 & 1,55 & 1,55 & 4,97 \\
\hline $\mathrm{CV}(\%)$ & 1,59 & 3,35 & 5,05 & 10,88 \\
\hline \multicolumn{5}{|l|}{ Espaçamentos (E) } \\
\hline $0,90 \mathrm{~m}$ & $52,51 \mathrm{a}$ & $31,74 \mathrm{a}$ & $20,76 \mathrm{a}$ & $32,34 \mathrm{a}$ \\
\hline $0,45 \mathrm{~m}$ & $52,10 \mathrm{a}$ & $31,12 \mathrm{a}$ & $20,97 \mathrm{a}$ & $29,70 \mathrm{~b}$ \\
\hline DMS Tukey & 0,53 & 1,37 & 0,99 & 2,42 \\
\hline $\mathrm{CV}(\%)$ & 1,02 & 4,36 & 4,72 & 7,76 \\
\hline \multicolumn{5}{|l|}{ Teste F } \\
\hline $\mathrm{SC}$ & $5,43 * *$ & $4,15 *$ & $0,98^{\text {ns }}$ & $3,64 *$ \\
\hline $\mathrm{E}$ & $5,86^{\mathrm{ns}}$ & $2,02^{\mathrm{ns}}$ & $0,43^{\text {ns }}$ & $12,03 *$ \\
\hline $\mathrm{SC} \times \mathrm{E}$ & $1,93^{\text {ns }}$ & $0,90^{\text {ns }}$ & $1,62^{\mathrm{ns}}$ & $0,61^{\text {ns }}$ \\
\hline
\end{tabular}

Médias seguidas pela mesma letra minúscula na coluna não diferem entre si pelo teste Tukey a 5\% de probabilidade; *, ** significativo a 5 e $1 \%$ de probabilidade, respectivamente e ns - não significativo pelo teste $\mathrm{F}$.

ções estudadas afetam na formação e composição das espigas.

O número de grãos por espiga foi influenciado apenas pelos sistemas de cultivo (Tabela 4). O cultivo de Milho $+C$. juncea apresentou redução no número de grãos quando comparado ao Milho exclusivo, que não diferiu do consórcio com "mix" (crotalárias) e C. ochroleuca e Milho + C. spectabilis. A massa de 1.000 grãos não foi alterada pelos sistemas de cultivo e espaçamentos (Tabela 4), o que reforça o encontrado por Stacciarini et al. (2010), que não há influência na característica avaliada para os espaçamentos entrelinhas de milho de 0,45 e 0,90 m. Nesse sentido, De- métrio et al. (2008) verificaram que a massa de 1.000 grãos é mais fortemente influenciada pela genética do material utilizado.

A prolificidade foi influenciada pelo sistema de cultivo de Milho $+C$. juncea, que apresentou valores inferiores se comparado ao dos sistemas de Milho exclusivo e Milho $+C$. spectabilis, que não diferiram significativamente dos demais (Tabela 4). Já os espaçamentos não tiveram influência nos valores de prolificidade avaliados.

Cabe salientar que os sistemas de cultivo de milho com $C$. juncea apresentaram redução do número de espigas por planta (prolificidade do milho) e do 
Tabela 4. Número de grãos por espiga, massa de 1.000 grãos, produtividade e prolificidade do milho.

\begin{tabular}{|c|c|c|c|c|}
\hline Tratamentos & $\begin{array}{l}\mathrm{N}^{\circ} \text { de grãos } \\
\text { por espiga }\end{array}$ & $\begin{array}{c}\text { Massa de } \\
1.000 \text { grãos } \\
\text { (g) }\end{array}$ & $\begin{array}{l}\text { Prolificidade do } \\
\text { milho }\end{array}$ & Produtividade $(\mathrm{t})$ \\
\hline \multicolumn{5}{|l|}{ Sistemas de cultivo (SC) } \\
\hline Milho $+C$. juncea & $544,9 \mathrm{~b}$ & $246,81 \mathrm{a}$ & $0,84 \mathrm{~b}$ & $11,21 \mathrm{~b}$ \\
\hline Milho + C. spectabilis & $591,1 \mathrm{ab}$ & $260,21 \mathrm{a}$ & $0,93 \mathrm{ab}$ & $14,77 \mathrm{a}$ \\
\hline Milho $+C$. ochroleuca & $596,4 \mathrm{a}$ & $256,71 \mathrm{a}$ & $0,94 \mathrm{a}$ & $13,87 \mathrm{a}$ \\
\hline Milho + "mix" (crotalárias) & $609,0 \mathrm{a}$ & $253,58 \mathrm{a}$ & $0,95 \mathrm{a}$ & $13,87 \mathrm{a}$ \\
\hline Milho exclusivo & $619,0 \mathrm{a}$ & $256,21 \mathrm{a}$ & $0,92 \mathrm{ab}$ & $14,24 \mathrm{a}$ \\
\hline DMS Tukey & 47,18 & 19,54 & 0,09 & 2,210 \\
\hline $\mathrm{CV}(\%)$ & 5,40 & 5,20 & 6,69 & 10,96 \\
\hline \multicolumn{5}{|l|}{ Espaçamentos (E) } \\
\hline $0,90 \mathrm{~m}$ & $608,6 \mathrm{a}$ & $251,76 \mathrm{a}$ & $0,92 \mathrm{a}$ & $13,49 \mathrm{a}$ \\
\hline $0,45 \mathrm{~m}$ & 575,6 a & $257,64 \mathrm{a}$ & $0,91 \mathrm{a}$ & $13,86 \mathrm{a}$ \\
\hline DMS Tukey & 76,74 & 9,28 & 0,04 & 1,29 \\
\hline $\mathrm{CV}(\%)$ & 12,88 & 3,62 & 5,25 & 9,39 \\
\hline \multicolumn{5}{|l|}{ Teste F } \\
\hline $\mathrm{SC}$ & $6,35 * *$ & $1,1406^{\mathrm{ns}}$ & $3,69 *$ & $7,10 * *$ \\
\hline $\mathrm{E}$ & $1,88^{\mathrm{ns}}$ & $4,0483^{\text {ns }}$ & $0,25^{\text {ns }}$ & $0,82^{\text {ns }}$ \\
\hline $\mathrm{SC} \times \mathrm{E}$ & $1,84^{\mathrm{ns}}$ & $2,0785^{\mathrm{ns}}$ & $0,22^{\text {ns }}$ & $1,11^{\text {ns }}$ \\
\hline
\end{tabular}

Médias seguidas pela mesma letra minúscula na coluna não diferem entre si pelo teste Tukey a 5\% de probabilidade; *, ** significativo a 5 e $1 \%$ de probabilidade, respectivamente e ns - não significativo pelo teste $\mathrm{F}$.

número de grãos por espiga, fatores que influenciam diretamente na produtividade do cereal.

A produtividade do milho foi influenciada pelos sistemas de cultivo (Tabela 4). O sistema de Milho $+C$. juncea reduziu a produtividade do cereal quando comparado aos outros sistemas. O mesmo foi observado por Gitti et al. (2012), que constataram resultados inferiores para o consórcio, quando a espécie de $C$. juncea foi semeada de forma simultânea com o milho.

Contudo, os espaçamentos não influenciaram na produtividade do cereal, o que reforça os resultados verificados por Kappes et al. (2011), em que a utilização dos espaçamentos entrelinhas de 0,45 e 0,90 m não apresentou diferença para a produtividade da cultura. Observaram-se valores médios de produtividade entre 11,21 e 14,24 $\mathrm{tha}^{-1}$, o que pode ser explicado pelas condições climáticas favoráveis, com destaque para boa distribuição de chuvas, especialmente nos estádios reprodutivos. A precipitação acumulada durante o enchimento de grãos foi de 177,5 $\mathrm{mm}$ e durante o ciclo do milho de 595,8 $\mathrm{mm}$, resultados que corroboram com Kappes et al. (2011), que ressaltaram que a exigência para altas produtividades do milho é de 300 a $500 \mathrm{~mm}$. Em relação à temperatura, foi registrada a média de $24,3{ }^{\circ} \mathrm{C}$, que se enquadra 
na faixa considerada adequada para a cultura, entre 24 e $30{ }^{\circ} \mathrm{C}$. Outros fatores que ajudam a explicar a alta produtividade observada é a sanidade do híbrido utilizado, que resultou em baixa incidência de pragas e doenças, e seu elevado potencial produtivo, característica genética do material.

$\mathrm{O}$ teor de $\mathrm{N}$ na palhada não foi alterado em virtude dos sistemas de cultivo ou dos espaçamentos (Tabela 5). Observou-se uma variação entre 7,61 e $8,22 \mathrm{~g} \mathrm{~kg}^{-1}$, valores semelhantes aos constatados por Silva et al. (2008) para os teores na palhada de milho. Por outro lado, a massa seca da palhada sofreu alterações em função dos sistemas de cultivo. Nota-se que o sistema de Milho exclusivo produziu uma quantida- de de palhada inferior se comparado aos consórcios com "mix" (crotalárias), C. juncea e C. spectabilis, que não diferem do consórcio de Milho $+C$. juncea. É importante salientar que o sistema com a $C$. juncea apresentou os valores mais elevados, fato que se relaciona com as características morfológicas da espécie, observadas na avaliação de altura final da crotalária (Tabela 2). Os espaçamentos, por sua vez, não influenciaram nos resultados de massa seca de palhada.

Com relação ao acúmulo de $\mathrm{N}$ na palhada, observou-se que não há alterações significativas em função dos diferentes sistemas de cultivo ou espaçamentos (Tabela 5). No entanto, a palhada oriunda do consórcio Milho $+C$. juncea proporcionou os maiores

Tabela 5. Teor de N na palhada, massa seca da palhada e acúmulo de N na palhada.

\begin{tabular}{|c|c|c|c|}
\hline Tratamentos & $\begin{array}{c}\text { Teor de N na } \\
\text { palhada }\left(\mathrm{g} \mathrm{kg}^{-1}\right)\end{array}$ & $\begin{array}{c}\text { Massa seca da } \\
\text { palhada }(\mathrm{t})\end{array}$ & $\begin{array}{l}\text { Acúmulo de } \mathrm{N} \text { na } \\
\text { palhada }\left(\mathrm{kg} \mathrm{ha}^{-1}\right)\end{array}$ \\
\hline \multicolumn{4}{|l|}{ Sistemas de cultivo (SC) } \\
\hline Milho + C. juncea & $7,61 \mathrm{a}$ & $9,53 \mathrm{a}$ & $70,91 \mathrm{a}$ \\
\hline Milho + C. spectabilis & $7,96 \mathrm{a}$ & $8,13 \mathrm{ab}$ & $65,15 \mathrm{a}$ \\
\hline Milho + C. ochroleuca & $8,22 \mathrm{a}$ & $8,23 \mathrm{ab}$ & $66,40 \mathrm{a}$ \\
\hline Milho + "mix" (crotalárias) & $7,78 \mathrm{a}$ & $8,48 \mathrm{ab}$ & $66,29 \mathrm{a}$ \\
\hline Milho exclusivo & $7,96 \mathrm{a}$ & $7,19 \mathrm{~b}$ & $56,56 \mathrm{a}$ \\
\hline DMS Tukey & 1,95 & 1,602 & 22,48 \\
\hline CV $(\%)$ & 16,7 & 13,08 & 23,44 \\
\hline \multicolumn{4}{|l|}{ Espaçamentos (E) } \\
\hline $0,90 \mathrm{~m}$ & 8,15 a & $8,42 \mathrm{a}$ & $67,06 \mathrm{a}$ \\
\hline $0,45 \mathrm{~m}$ & $7,66 \mathrm{a}$ & 8,19 a & $63,07 \mathrm{a}$ \\
\hline DMS Tukey & 2,31 & 4,30 & 14,94 \\
\hline CV $(\%)$ & 29,13 & 51,46 & 22,83 \\
\hline \multicolumn{4}{|l|}{ Teste F } \\
\hline $\mathrm{SC}$ & $0,23^{\mathrm{ns}}$ & $4,77 * *$ & $0,94^{\mathrm{ns}}$ \\
\hline $\mathrm{E}$ & $0,45^{\mathrm{ns}}$ & $0,02^{\mathrm{ns}}$ & $0,72^{\text {ns }}$ \\
\hline $\mathrm{SC} \times \mathrm{E}$ & $0,87^{\mathrm{ns}}$ & $1,58^{\text {ns }}$ & $1,02^{\text {ns }}$ \\
\hline
\end{tabular}

Médias seguidas pela mesma letra minúscula na coluna não diferem entre si pelo teste Tukey a 5\% de probabilidade; *,** significativo a 5 e $1 \%$ de probabilidade, respectivamente e ns - não significativo pelo teste $\mathrm{F}$. 
valores médios de acúmulo, sendo 25,3\% superior ao milho exclusivo. Nesse sentido, é válido analisar os resultados alcançados sob a ótica de otimizar os sistemas agrícolas, tornando-os mais sustentáveis, através dos benefícios proporcionados pelos adubos verdes, aumento de palha para utilização no sistema plantio direto e a possibilidade de redução do uso de fertilizantes nitrogenados para a cultura subsequente.

\section{Conclusões}

O consórcio de milho com a $C$. juncea reduz a produtividade do cereal. No entanto, a sua utilização no "mix" com as demais espécies, em densidade de semeadura menor, é viável na modalidade estudada. Recomenda-se o uso das espécies de C. spectabilis, C. ochroleuca e do "mix" para o consórcio com o milho.

Os espaçamentos entrelinhas de milho de 0,45 e 0,90 m não influenciam os atributos de crescimento, os componentes de produção, a produtividade desse cereal e a palhada resultante dos sistemas de cultivo utilizados. Por sua vez, a altura final das espécies de crotalárias é reduzida pela adoção do espaçamento de $0,45 \mathrm{~m}$.

Os sistemas de cultivo em consórcio com espécies de crotalárias proporcionam maior massa seca de palhada em comparação ao milho cultivado de forma exclusiva, embora o acúmulo de nitrogênio na palhada não seja alterado.

\section{Agradecimentos}

Ao Conselho Nacional de Desenvolvimento Científico e Tecnológico (CNPq) pela bolsa de iniciação científica (PIBIC) concedida ao primeiro autor.

\section{Referências}

BORGHI, E.; CRUSCIOL, C. A. C. Produtividade de milho, espaçamento e modalidade de consorciação com Brachiaria brizantha em sistema plantio direto. Pesquisa Agropecuária Brasileira, Brasília, DF, v. 42, n. 2, p. 163171, 2007. DOI: 10.1590/S0100-204X2007000200004.

CHIEZA, E. D.; GUERRA, J. G. M.; ARAÚJO, E. S.; ESPÍNDOLA, J. A.; FERNANDES, R. C. Produção e aspectos econômicos de milho consorciado com Crotalaria juncea L. em diferentes intervalos de semeadura, sob manejo orgânico. Revista Ceres, Viçosa, MG, v. 64, n. 2, p. 189-196, 2017.

DOI: $10.1590 / 0034-737 \times 201764020012$.

CANTARELLA, H., RAIJ, B. van; CAMARGO, C. E. O. Cereais. In: RAIJ, B. van; CANTARELLA, H.; QUAGGIO, J. A.; FURLANI, A. M. C. (Ed.). Recomendação de adubação e calagem para o Estado de São Paulo. 2. ed. Campinas: Instituto Agronômico, 1997. p. 43-71.

COELHO, A. M.; FRANÇA, G. E.; PITTA, G. V. E.; ALVES, V. M. C. Cultivo do milho: diagnose foliar do estado nutricional da planta. Sete Lagoas: Embrapa Milho e Sorgo, 2002. 5 p. (Embrapa Milho e Sorgo. Comunicado Técnico, 45).

DEMÉTRIO, C. S.; FORNASIERI FILHO, D.; CAZETTA, J. O.; CAZETTA, D. A. Desempenho de híbridos de milho submetidos a diferentes espaçamentos e densidades populacionais. Pesquisa Agropecuária Brasileira, Brasília, DF, v. 43, n. 12, p. 1691-1697, 2008. DOI: 10.1590/S0100-204X2008001200008.

GITTI, D. C.; ARF, O.; VILELA, R. G.; PORTUGAL, J. R.; KANEKO, F. H.; RODRIGUES, R. A. F. Épocas de semeadura de crotalária em consórcio com milho. Revista Brasileira de Milho e Sorgo, Sete Lagoas, v. 11, n. 2, p. 156-168, 2012.

DOI: 10.18512/1980-6477/rbms.v11n2p156-168.

HEINRICHS, R.; VITTI, G. C.; MOREIRA, A.; FANCELLI, A. L. Produção e estado nutricional do milho em 
cultivo intercalar com adubos verdes. Revista Brasileira de Ciência do Solo, Viçosa, MG, v. 26, n. 1, p. 225-230, 2002.

DOI: $10.1590 / \mathrm{S} 0100-06832002000100023$.

KANEKO, F. H.; ARF, O.; GITTI, D. C.; ARF, M. V.; CHIODEROLLI, C. A.; KAPPES, C. Manejo do solo e do nitrogênio em milho cultivado em espaçamentos reduzido e tradicional. Bragantia, Campinas, v. 69, n. 3, p. 677-686, 2010. DOI: 10.1590/S0006-87052010000300020.

KAPPES, C.; ANDRADE, J. A. C.; ARF, O.; OLIVEIRA, A. C.; ARF, M. V.; FERREIRA, J. P. Desempenho de híbridos de milho em diferentes arranjos espaciais de plantas. Bragantia, Campinas, v. 70, n. 2, p. 334-343, 2011.

DOI: 10.1590/S0006-87052011000200012.

KAPPES, C.; ZANCANARO, L. Sistemas de consórcios de braquiária e de crotalárias com a cultura do milho. Revista Brasileira de Milho e Sorgo, Sete Lagoas, v. 14, n. 2, p. 219-234, 2015.

DOI: 10.18512/1980-6477/rbms.v14n2p219-234.

OLIVEIRA, P.; KLUTHCOUSKI, J.; FAVARIN, J. L.; SANTOS, D. C. Sistema Santa Brígida - tecnologia Embrapa: consorciação de milho com leguminosas. Santo Antônio, de Goiás: Embrapa Arroz e Feijão, 2010. 16 p. (Embrapa Arroz e Feijão. Circular Técnica, 88).

PEREIRA, L. C.; FONTANETTI, A.; BATISTA, J. N.; GALVÃO, J. C. C.; GOULART, P. L. Comportamento de cultivares de milho consorciados com Crotalaria juncea: estudo preliminar. Revista Brasileira de Agroecologia, Pelotas, v. 6, n. 3, p. 191-200, 2011.

RAIJ, B. van; CANTARELLA, H. Milho para grão e silagem. In: RAIJ, B. van; CANTARELLA, H.; QUAGGIO, J. A.; FURLANI, A. M. C. (Ed.). Recomendação de adubação e calagem para o Estado de São Paulo. 2. ed. Campinas: IAC, 1997, p. 56-59. (Boletim Técnico, 100).
SILVA, E. C.; MURAOKA, T.; BUZETTI, S.; ESPINAL, F. S. C.; TRIVELIN, P. C. O. Utilização do nitrogênio da palha de milho e de adubos verdes pela cultura do milho. Revista Brasileira de Ciência do Solo, Viçosa, MG, v. 32, p. 2853-2861, 2008.

DOI: 10.1590/S0100-06832008000700032.

SILVA, A. F.; SCHONINGER, E. L.; CAIONE, G.; KUFFEL, C.; CARVALHO, M. A. C. Produtividade de híbridos de milho em função do espaçamento e da população de plantas em sistema de plantio convencional. Revista Brasileira de Milho e Sorgo, Sete Lagoas, v. 13, n. 2, p. 162$173,2014$.

DOI: 10.18512/1980-6477/rbms.v13n2p162-173.

SILVA, P. C. G.; FOLONI, J. S. S.; FABRIS, L. B.; TIRITAN, C. S. Fitomassa e relação $\mathrm{C} / \mathrm{N}$ em consórcios de sorgo e milho com espécies de cobertura. Pesquisa Agropecuária Brasileira, Brasília, DF, v. 44, n. 11, p. 1504-1512, 2009. DOI: 10.1590/S0100-204X2009001100019.

STACCIARINI, T. C. V.; CASTRO, P. H. C.; BORGES, M. A.; GUERIN, H. F.; MORAES, P. A. C.; GOTARDO, M. Avaliação de caracteres agronômicos na cultura do milho mediante a redução do espaçamento entrelinhas e aumento da densidade populacional. Revista Ceres, Viçosa, MG, v. 57, n. 4, p. 516-519, 2010.

DOI: 10.1590/S0034-737X2010000400012.

TAKASU, A. T.; RODRIGUES, R. A. F.; GOES, R. J.; ARF, O.; HAGA, K. I. Desempenho agronômico do milho sob diferentes arranjos populacionais e espaçamentos entrelinhas. Agrarian, Dourados, MS, v. 7, n. 23, p. 34-41, 2014.

WUTKE, E. B.; CALEGARI, A.; WILDNER, L. P. Espécies de adubos verdes e plantas de cobertura e recomendações para seu uso. In: LIMA FILHO, O. F.; AMBROSANO, E. J.; ROSSI, F.; CARLOS, J. A. D. (Ed.). Adubação verde e plantas de cobertura no Brasil: fundamentos e prática. Brasília, DF: Embrapa, 2014. p. 59-167. 